\title{
PÕDERPÓRNIKALISED (COL. LUCANIDAE) PLATYCERUS CARABOIDES (L.) JA PL. CAPREA (DE GEER) EESTIS
}

Väikesest pōderpōrniklaste sugukonnast, kuhu kuulub kogu maailmas umbes 700 liiki, neist Palearktises umbes 85 , tuntakse Eesti faunas seni ainult 3 kõdunevas lehtpuidus elavat liiki 3 perekonnast. Need on: põderpõrnikas (Lucanus cervus L.), kitspōrnikas (Platycerus caraboides L.) ja sarvpõrnikas (Sinodendron cylindricum L.). Esimesest on teada ainult 3 juhuslikku leidu Saaremaalt ja Viljandi ümbrusest, teised kaks on enam levinud.

Rootsi entomoloog Th. Palm (1956), revideerides Platycerus caraboides L. nime all tuntud liiki, tegi kindlaks, et selle Linné' poolt 1758. aastal kirjeldatud liigi all on seni kokku vōetud 2 üksteisest hästi erinevat liiki. B. O. Landin (1956), revideerides Linné' originaalkogude materjale, selgitas välja, et Linné' kirjeldatud tüüp erineb de Geeri (1774) kirjeldatud tüübist. Järelikult on meil tegu ligemale 2 sajandit kestnud süstemaatikute eksitusega, sest tänini käsitati de Geeri nimetust sünonüümina.

Perekonnast Platycerus Geoffroy (1782) (= Systenocerus Wse 1883) tunti seni kogu Euroopast ainult liiki caraboides L. ja Kaukaasiast kirjeldatud liiki $\mathrm{Pl}$. caucasicus Parry (1864). Ulejäänud kaks perekonna liiki pärinevad Jaapanist ja Süüriast.

Kollektiivliigi leide Eestist on autorile teadaolevas kirjanduses mainitud kolmel korral: Seidlitz (1891, 130), Haberman (1936, 22) ja Szeliga-Mierzejewski (1942, 217). ENSV TA Zooloogia ja Botaanika Instituudi kogudes leidus nimetuse all Platycerus caraboides L. üldse 81 isendit, neist 44 ô $\hat{o}$ ja $37 \%$ ㅇ. Loomad on kogutud alates 1829. aastast kuni tänapäevani 15 koguja poolt 29 leiukohast.

Materjali läbitöötamisel selgus, et ka meil on tegemist mõlema liigiga, kusjuures $P l$. caprea (de Geer) on enam levinud ja arvukam. Pl. caraboides (L.) on seni kindlaks tehtud vaid mandril, kus ta levik piirdub peamiselt Kagu- ja Lääne-Eestiga (joon. 1 ja 2). On ka môlema liigi leide samadest leiukohtadest. Kuna liikide areaalid on praegu veel välja selgitamata, avaldame järgnevalt liikide läbitöötamise senised tulemused Eesti kohta.

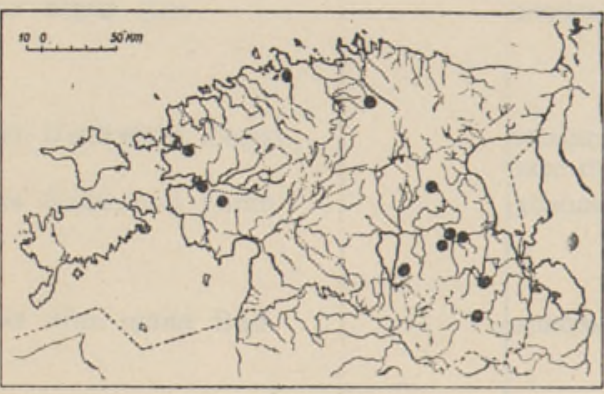

Joon. 1. Väikese kitspõrnika (Pl. caraboides L.) levik Eestis.

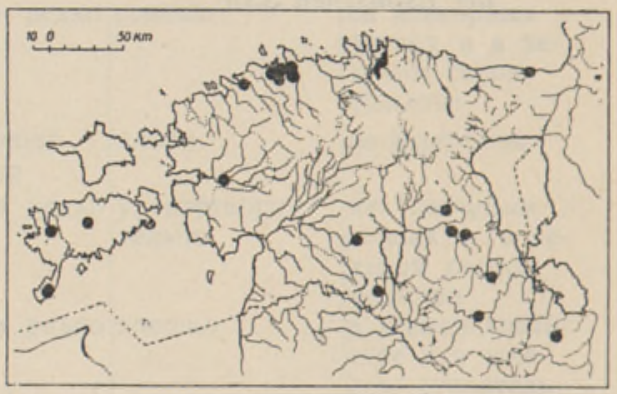

Joon. 2. Suure kitspōrnika (Pl. caprea de Geer) levik Eestis.

\section{Platycerus caraboides (L.)}

Oldlevik: Rootsi lōuna- ja keskosades, üksikleide ka Lääne-Saksamaalt.

Eestis (joon. 1): Lääne-Nigula, Matsalu lahe ümbrus, Keblaste tammik, Kose, Kurge, Pikkjärve luht, Tartu, Kabina, Ropka, Valguta, Pōlva ja Võru - 16 isendit. Täpsustamata leiukohtadega (etikettidega \&Livonia» ja «Curonia») ning etikettideta leide 7 isendit. Kokku 23 isendit, neist 5 ô ồ .

$$
\begin{aligned}
& \text { Pikkus ô } \hat{o} \quad 10,8-13,0 \mathrm{~mm} \text {, keskmine } 11,8 \mathrm{~mm} \text {, } \\
& \text { ㅇํ } 9,4-13,5 \mathrm{~mm} \text {, keskmine } 11,8 \mathrm{~mm} \text {. }
\end{aligned}
$$

Valmikud esinevad maist kuni septembrini; nende arvukus on kōige suurem mais, sügiseni langeb pidevalt. Leiukohad peamiselt kõdunevate lehtpuude kändudes ja tüvedes koore all. Emaloomadest on $2 / 3$ heledate jalgadega ab. rufipes Hbst.

\section{Platycerus caprea (de Geer)}

Oldlevik: eriti Põhja-Rootsis, Soome lōuna- ja kaguosades, Taanis ja Lääne-Sakșamaal. 


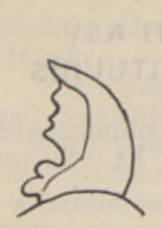

1

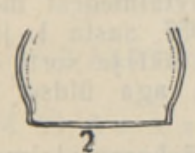

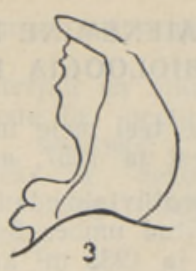

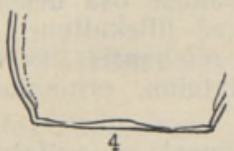

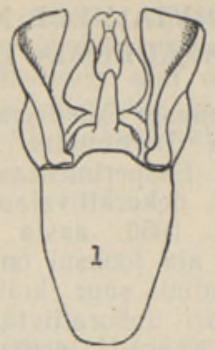

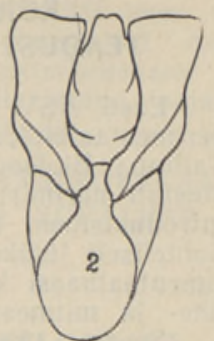

Joon. 4. Pl. caraboides aedeagus: 1 - ventraalselt, 2 - dorsaalselt.

Joon. 3. Kitspōrnikate suised (mandiiblid) ja rinnakilbi tagaserv: I ja $2-P l$. caraboides, 3 ja $4-P l$. caprea.

Eestis (joon. 2): Mōntu, Karujärve, Tikka ja Saaremaa, Rumba, Laulasmaa, Veskimäe, Nōmme, Tallinn, Pirita, Kose, Viljandi, Tõrva, Oru, Saadjärve, Tartu, Vana-Kuuste, Pōlva, Võru. Täpsustamata leide (etikettidega «Curonia», «Livonia», «Estonia») ja etikettideta - 10 isendit. Pihkva oblastist Mõla järvelt 1 ô. Kokku 58 isendit, neist $39 \hat{o} \hat{o}$.

Pikkus tô $\hat{o}$ 11,4-14,8 mm, keskmine $13,2 \mathrm{~mm}$, 우 ㅇ $12,0-14,9 \mathrm{~mm}$, keskmine $12,9 \mathrm{~mm}$.

Valmikud maist septembrini: $60 \%$ leidudest mais, $24 \%$ juunis. Lendu tähistatud juunis. Leiukohad nagu eelmisel.

Mõlema liigi eritlemiseks anname määramistabeli Palmi (1956) järgi, mõningate täiendustega:

1 (2) Väiksem, pikkus (mandiiblitega) 9,4-13,5 mm, keskmine 11,8 mm. Mandiiblid vähem etteulatuvad, jässakamad, välisserv ühtlasemalt kaarjas, siseserval hammastevaheline sälk kitsam (joon. $3 ; 1$ ). Värvus sinine kuni roheline, tagakeha alapoolel puhuti punakaspruun. Isaloomadel jalad mustad, emaloomadel sageli ruuged (ab. rufipes Hbst.). Rinnakilp lamedam, küljed enne taganurki tavaliselt niverdunud, taganurgad seetōttu täisnurksed. Basaalservis tugev, ühtlaselt välja kujunenud (joon. $3 ; 2$ ). Rinnakilbi punktiir enam-vähem tihe, läige nōrgem. Puhuti rinnakilbil 2 tugevat sümmeetrilist punkti. Aedeagus joon. 4. Pl. caraboides (L.).

2 (1) Suurem, pikkus 11,4-14,9 mm, keskmine ô ô 13,2, 우 우 12,9 mm. Mandiiblid (eriti isaloomadel) enam etteulatuvad, saledamad. Nende välisserv basaalosas tugevamini kaardunud kui tipmiselt. Siseserval hammastevaheline sälk lai, kaarjas. (joon. $3 ; 3$ ). Värvus enam sinine kui roheline, jalad tumedad. Rinnakilp kumeram, taganurgad tavaliselt tömbid, külgserv nende ees niverduseta või õige nồrgalt niverdunud. Basaalservis nörgem, keskosast kahele poole veidi lame (joon. $3 ; 4)$. Rinnakilbi punktiir höredam, pind läikivam. Sümmeetrilised punktid võivad esineda Aedeagus joon. 5. Pl. caprea (de Geer).

\section{KIRJANDUS}

D e Geer, Ch., 1774. Mémoires pour servir à l'Histoire des Insectes IV. Sfockholm.

$\mathrm{H}$ a b e rma n, H., 1936. Andmeid Kuusnōmme bioloogiajaama ümbruse mardikalistest. Eesti Loodusteaduse Arhiiv II, 16, 1, lk. 1-32. Tartu.

$\mathrm{L}$ a ndi n, B. O., 1956. The Linnean Species of Lamellicornia, described in «Systema Naturae», Ed. X (1758). (Col.). Entomol. Tidskr., 77, 1, lk. 1-18.

L i n n é, C., 1758. Systema Naturae. Ed. X. Holmiae.

P a $1 \mathrm{~m}$, Th., 1956.Systenocerus caraboides L. och cribratus. Muls. (Col., Lucanidae). Entomol. Tidskr., $77,1,1 \mathrm{k} .19-24$.

S e i d 1 i t z, G., 1891. Fauna Baltica. Kaefer. Königsberg.

$\mathrm{Sz}$ li g a-Mierzejewski, W., 1942. Verzeichnis der Käfer Ösels in meiner Insektensammlung. Korrespondenzbl. Naturf. Ver. 64, lk. 180-230. Riga.

W i n k l e r, A., Catalogus Coleopterorum regionis palaearcticae. 1924-1932. Wien. 